\section{Commentary: The toughest pill to swallow? Nonvitamin K oral anticoagulants and cardiac surgery}

\author{
HelenMari Merritt-Genore, DO
}

Over the past 10 years, nonvitamin $\mathrm{K}$ oral anticoagulants (NOACs) have exploded in global popularity, with prescriptions for NOACs now exceeding those for warfarin for treating nonvalvular atrial fibrillation and pulmonary embolus. In this Expert Review, Waterford and $\mathrm{Ad}^{1}$ examine contemporary data for NOACs as pertinent to cardiac surgery.

An important consideration brought to light is the use of reversal agents for NOACs in urgent surgeries. Initially welcomed by surgeons for rescue in situations when urgent reversal of anticoagulation was necessary (without the volume of plasma), these agents have not been studied in unstable angina or myocardial infarction, and thus their safety in these situations is relatively unknown. The reversal medications also carry significant warnings for increased rates of thromboembolic arterial and venous events, which may be catastrophic complications in the postoperative period.

In addition, the Society of Thoracic Surgeons database has not historically tracked the use of nonplatelet anticoagulants before or after cardiac surgery in terms of perioperative outcomes and complications. Cardiac surgeons have relied on the Society of Thoracic Surgeons database for robust patient characteristics and outcomes in other realms, leaving a knowledge gap regarding patient care and the use of NOACs and reversal agents and their implications in our field.

There are also certain limitations and nuances for which particular NOACs might be most appropriate for a certain patient, and many surgeons may be uncomfortable managing medication subtleties, in addition to other ever-changing practices of our specialty. Just one such example is the

From the Methodist Physicians' Clinic, Omaha, Neb.

Disclosures: The author reported no conflicts of interest.

The Journal policy requires editors and reviewers to disclose conflicts of interest and to decline handling or reviewing manuscripts for which they may have a conflict of interest. The editors and reviewers of this article have no conflicts of interest.

Received for publication April 5, 2021; revisions received April 5, 2021; accepted for publication April 6, 2021; available ahead of print April 20, 2021.

Address for reprints: HelenMari Merritt-Genore, DO, Methodist Physicians' Clinic,

1120 S 103rd Plaza, Omaha, NE 68114 (E-mail: Helenmari.merritt@ gmail.com). J Thorac Cardiovasc Surg 2022;163:2153-4

$0022-5223 / \$ 36.00$

Copyright (c) 2021 by The American Association for Thoracic Surgery

https://doi.org/10.1016/j.jtcvs.2021.04.003

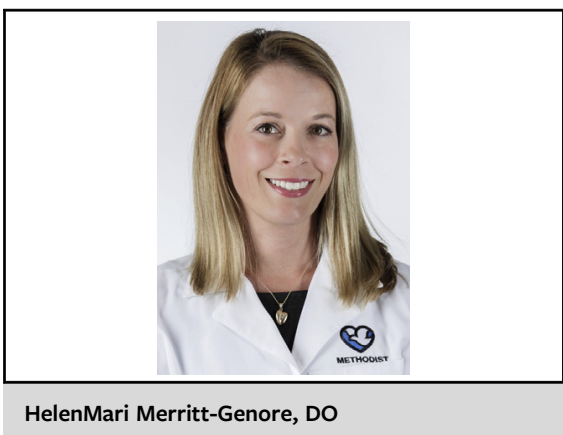

CENTRAL MESSAGE

Many uncertainties persist regarding the use of oral anticoagulants in cardiac surgery. Further studies are needed to define appropriate usage guidelines in our field.

current guideline suggesting alternative strategies for obese patients. Although our specialty certainly encounters plenty of obesity, adjustment in dosing or monitoring levels of efficacy does not seem to be common practice.

In addition, the primary indication for anticoagulation (in the absence of a mechanical valve) is atrial fibrillation in the postoperative period, either newly diagnosed or chronic. A recent large meta-analysis found improved rates of embolic events and all-cause mortality in patients who underwent left atrial appendage (LAA) occlusion at the time of cardiac surgery. $^{3}$ This highlights the controversy of whether the LAA should be routinely addressed intraoperatively and if this would potentially decrease the urgency of postoperative anticoagulation - and if so, which method of LAA occlusion should be used?

Finally, although the $\mathrm{CHA}_{2} \mathrm{DS}_{2}$-VASc score has been well validated to predict stroke in patients, ${ }^{4}$ it has not been common practice to apply any scoring criteria to the medication decisions in the perioperative period. Likewise, the HAS-BLED and HEMORR ${ }_{2}$ HAGES scores for major bleeding risk stratification were created in the previous decade and did not include postoperative cardiac surgery patients or monitoring of INR. ${ }^{5,6}$ The decision to initiate dual-antiplatelet or single-antiplatelet therapy plus or minus NOACs also has very limited guidance. With a growing population of elderly patients who are at risk for both bleeding and thrombotic events, the clinician is left with 
scant guidelines for these decisions, the implications of which are major.

In closing, we need further well-designed studies and risk stratification tools that have been specifically validated in our field to direct practice for the NOACs in cardiac surgery.

\section{References}

1. Waterford SD, Ad N. Nonvitamin K oral anticoagulants in cardiac surgery: what cardiothoracic surgeon needs to know 2.0. J Thorac Cardiovasc Surg. 2022;163: 2145-52.

2. Pabinger I, Brenner B, Kalina U, Knaub S, Nagy A, Ostermann H, et al. Prothrombin complex concentrate (Beriplex $\mathrm{P} / \mathrm{N}$ ) for emergency anticoagulation reversal: a prospective multinational clinical trial. J Thromb Haemost. 2008;6:622-31.
3. Ibrahim AM, Tandan N, Koester C, Al-Akchar M, Bhandari B, Botchway A, et al. Meta-analysis evaluating outcomes of surgical left atrial appendage occlusion during cardiac surgery. Am J Cardiol. 2019;124:1218-25.

4. Saliba W, Gronich N, Barnett-Griness O, Rennert G. The role of $\mathrm{CHADS}_{2}$ and $\mathrm{CHA}_{2} \mathrm{DS}_{2}$-VASc scores in the prediction of stroke in individuals without atrial fibrillation: a population-based study. J Thromb Haemost. 2016;14: 1155-62.

5. Gage BF, Yan Y, Milligan PE, Waterman AD, Culverhouse R, Rich MW, et al. Clinical classification schemes for predicting hemorrhage: results from the National Registry of Atrial Fibrillation (NRAF). Am Heart J. 2006;151:713-9.

6. Pisters R, Lane DA, Nieuwlaat R, de Vos CB, Crijns HJG, Lip GYH. A novel user-friendly score (HAS-BLED) to assess 1-year risk of major bleeding in patients with atrial fibrillation: the Euro Heart Survey. Chest. 2010;138: 1093-100. 